\title{
Rethinking the Traditional "Faithfulness" after Deconstructing Centeredness
}

\author{
Chunhua Shen \\ School of Foreign Languages, Wuhan Polytechnic University, Wuhan, China \\ Corresponding author
}

\begin{abstract}
Among many translation criteria, "faithfulness" principle is the most popular and widely accepted by Chinese and Westerners. Traditional translation criteria emphasize "faithfulness" which is regarded as the most essential principle in translation process and is also accepted by most translators. This thesis, from the point of deconstruction, will discuss anew the traditional "faithfulness".
\end{abstract}

Keywords-deconstruction; traditional translation theories; faithfulness

\section{INTRODUCTION}

Translation is an ancient human activity, setting up a bridge among people with different language. And translators play a critical role in the communicative process of bilingual language. To make the communication more fluent and accessible among different culture, what principle translators should obey in translating is always under the discussion. About this issue, traditional translation theories hold the viewpoint that original texts should be put in the first place and translators are supposed to obey them without reserve. However, this kind of opinion becomes weaker and weaker under the attack of postmodernism and even face the danger of being discarded. Although some translators try to put forward new translation criteria to replace the traditional "faithfulness", all of them have not understand the true meaning of deconstruction and nor do they break away from the traditional fetter.

\section{II. “FAithFuLNESS” OF TRADITIONAL TRANSLATION THEORIES}

Both the first two phases belong to traditional translation theories, the later belongs to modern translation theories. The so-called "faithfulness" of traditional translation theories means that source texts are always at present when translators take up translation activities. In other words, the "faithfulness" under traditional translation theories is a theory that translators are absent in translating. It is a kind of practical activity without taking translators into consideration. The first stage mainly refers to Buddhist translation. Famous representatives such as Zhi Qian and Dao An who advocates literal translation, Kumarajiva who intends to free translation, Xuan Zang who epitomizes the Buddhist translation and thinks that translation must be both truthful and intelligible to the populace. These theories, formed in the early stage of traditional translation theories, basically maintain literal translation and word-forword translation. The second stage mainly refers to scientific translation in Qing Dynasty and the Republic of China(1912-
1949). This period was a transitional stage from old China to new China. There are some notable translators such as Linshu, Yanfu, Luxun, Fulei, and so on. In fact, Linshu knew nothing about English, but he had translated so many foreign novels through the way of friends' interpreting plus his understanding. Therefore, translated novels by him are not completely faithful to the original texts, but they are very popular with Chinese people in that these foreign novels are endowed with Chinese features. Though the translation skill he used was inclined to free translation, he still took the original text as his model. In his works, source texts are always in the first place. Later, the well-known translation theorist Yanfu, who put forward the theory of "faithfulness, expressiveness, elegance", laid a firm foundation for traditional translation theories. Before Yanfu, there were also a few translators that had studied translation criteria, however, they hadn't formed a systematic theory. It was not until Yanfu that China's translation field had a explicit translation standard.

After the May 4th Movement, there was a celebrated person named Lu Xun. He thought that translation should take two respects into consideration: making it understood and keeping the original flavor. But sometimes these two factors were difficult to be satisfactory at the same time, therefore he maintained the view of "rather 'faithfulness' than fluency", in other words, when the two factors have a conflict, he will select the later and give up the former. Obviously, he put original texts in the supreme place. At this period, in order to enlighten the silly citizen, many patriots began to find ways to save the nation and people. So some young people coming from middle class went to study abroad. Fu Lei is one of them. After studying in France, he came back to his mother-land and was engaged in literature translation especially French novel. Most works he translated were Balzac's such as Le Pere Goriot, Disillusionment trilogy, the Human Comedy and so on. "Fu Lei held that translation first must be faithful to original texts if it is requested to be faithful to target reader. How to do that? There are two points: first, translators should read carefully original texts and then turn the content into own understanding, meanwhile, experiencing the feeling of original authors; second, expression should convey the thoughts and style of original texts and the Chinese version must be amended repeatedly.”. Above-mentioned people, they are representatives of traditional translation theories. Their works and theories constitute a comprehensively traditional translation theory. 


\section{The Origin AND DEVELOPMENT OF DECONSTRUCTION}

\section{A. The Origin of Deconstruction}

In 1940s-1950s, the third revolution in science and technology took place around the world. With the rapid development of science and technology, great changes have taken place in daily life. The great improvement of living standard urges people to pursue higher spiritual state. Therefore, philosophy is increasingly growing, which shows that people are paying more attention to internal world. "Deconstruction" is born under this kind of background. "Deconstruction", as a kind of design style, flourished in the 1980s. But its philosophical origin can be traced back to 1967. A philosopher named Derrida (1930-2004), based on the criticism of the structuralism in linguistics, put forward the theory of "deconstruction". In Heidegger's view, the western history of philosophy is the history of metaphysics, its prototype is that "existence" would be a "present". By means of Heidegger's concept, Derrida refers to it as "present metaphysics". The ultimate, truthful and primary things constitute a series of "logos". All the people and objects must follow the operative logic of "logos", and "logos" is permanent, which is akin to "god's law". Deviating from the "logos" means falling into fallacy. However, what other deconstructionists and Derrida attack is this kind of ideological tradition called logos centralism.

"Deconstruction" critically inherits orthodox principles and standards of modernism. Using words of modernism reverses and reconstructs relationships among various existing vocabulary, and logically negates the traditional basic design principles (aesthetics, mechanics, functions), resulting in a new meaning. "Deconstruction" uses the idea of decomposition to emphasize reconstruction and the individual, and objects to the sense of fragment and uncertainty created by integrated whole.

\section{B. The Development of Deconstruction in Translation}

Throughout the history, translation has been keeping a strong relationship with philosophy. Whether traditional classic philosophy, modern linguistic philosophy or deconstruction philosophy involve a lot of translation theories. What's more, translation theories also contain the ways and application of philosophy. Therefore, both of them supplement each other. The appearance of "deconstruction" brings hope for those translators who want to get rid of the fetter of traditional translation theory. They not only regard "deconstruction" as their weapon against traditional standard but also take advantage of it to explore new translation norm. Since 1970s, with the appearance of "deconstruction", the focus of western translation schools began to be shifted from internal study to external study. For example, Even-zohar's poly-system theory and Toury's "norm theory". In order to emphasize the diachronic and synchronic interaction of social culture system, Zohar puts forward the concept of "dynamic structure" to explain the open parts and diachronic variables and heterogeneity of poly-system theory. The aim he created this terminology was to exactly express a dynamic and heterogeneous system concept, drawing a clear distinction with Saussure's synchronic points. As for "norm theory", there are three meanings: it abandons the idea of one-to-one of traditional translation theory and the possibilities of equivalence in literature and linguistics; it permits literary purport to participate translation activities; it shakes the idea that original texts have certain meanings. These two theories are more or less influenced by “deconstruction” in early stage. Later, the combination of translation theories and "deconstruction" continued to develop forward. In 1970s-1980s, Text Typology, Skopostheories, Translation Action and Function plus Loyalty slowly came into being. Reiss(1923- ) divided texts into three types: texts with information functions, texts with expression functions and texts with operative functions. She thought that different types of texts should use different translation skills. The appearance of Skopostheorie marked that the perspective of translation study shifted from linguistics and formalized translation theory to functional, social and cultural respects. The definition of Skopostheory is producing a text at target setting for a target purpose and target addressee in target circumstances.

\section{REINTERPRETATION OF “FAITHFULNESS” UNDER THE NOTION OF DECONSTRUCTION}

\section{A. Reinterpretation of "Faithfulness" from the Perspectives of Target Texts and Target Readers}

In the view of "deconstruction", translation standards can be varied. The center position of original texts has become very weak under the concept of "deconstruction". Here, from the perspective of deconstruction, we reexplain the "faithfulness" standard from the factors that influence the translation "faithfulness". First, we can look upon the reinterpretation of "faithfulness" from the point of view of translated texts and readers. As we know, providing that there is an obscure novel, even if possessing high literature value, if it does not meet a reader appreciating its value, it is still a pile of useless waste papers. However, if it has a good translated version that can find readers around the world for itself, then there is a great possibility for it to become an eternal classics in the world from an unknown small works. When a original text includes a lot of technical terms and high literature connotations, it cannot be translated according to the original text if the readers are very common people in that these people have not enough knowledge reserves to understand its content and background, therefore, it could not play huge influence on the common. In other words, actually, the translated text is not really faithful to the original text.

\section{B. Reinterpretation of "Faithfulness" from the Perspectives of Translators' Subjectivity}

Translators is the subject of translation activities where the translators can play their subjective initiative and consciously overcome the difficulties in the process of translating. To achieve translators' translation purpose, they can give play to their abilities of autonomy, purpose and creativity in the translated text. All translators in translation have certain purposes, but no matter what their purposes are, which finally are bound to be reflected in the target text and be conveyed through it. In addition, the abilities of translators expressing 
their subjectivity and finishing tasks in the translation practice depend on their attainments including their bilingual abilities and encyclopedic knowledge. As a willed individual, the translator must have their own in the process of translation. Huang Zhending, a professor, strictly divided translation into two parts: scientific and technological translation and literary translation, the former emphasizes the transmission of ideology and scientific and technological information, the latter pays attention to reproducing the original style and aesthetic concepts. Based on the above understanding, the purposes of translators will be roughly divided into two aspects: pursuing integrity and loyalty; focusing on the basic infidelity of text content.

If the translator not only wants to let the readers have an overall understanding for the cultural content, style and form of the original text, but also hope that original texts as a kind of foreign culture can enter into the target language culture so as to enrich and influence (sometimes may be "add" or "recreate” ) the target language culture. Translators' translation purpose reflected in translation is the fully and faithfully embodiment of the original text. Under this circumstance, the translator will try their best to make their versions as much as possible faithful to the original text in meaning, form and style, and even reaching the point where "the translated text is like the work of the original author". Due to high unity of human language in form and content, and cultural identity, the objective is very likely to be achieved.

\section{Reinterpretation of "Faithfulness" from the Perspective of Sponsors and Culture Differences}

Besides the above two factors, the cultural differences and sponsors are also important factors affecting the effects of translation "loyalty". Cultural differences between China and western countries can probably be summarized into the following five parts: geographical concepts, living customs, religious beliefs, values, and historical background. These differences will be reflected through language environment. For example, spend money like water ("water" will be translated into "soil" in Chinese); Don't quarrel with your bread and butter ("bread and butter" into "job” in Chinese); God helps those who help themselves("God" into "Heaven" in Chinese). These culture-loaded words and phrase translation may be right, at the very least, they ensure the transmission of semantic content of the original text, but the cultural imagery of the original text in the translation is completely lost. While if the translator keep the cultural imagery of the original text, it will lead to difficulties in the process the readers understand the text. Therefore, translators should choose different translation standard according to different requests and circumstance.

\section{CONCLUSION}

The traditional translation theory must be constantly innovated and injected new life. Only through this way can it continues to survive and develop in the world. Otherwise, it will become stale, hindering the emergence and development of the new theory. Under the impact of the deconstruction thoughts, quite a few researchers have arrived consensuses on new perspective, new ideas and new methods of translation studies. Under the perspective of deconstruction, the study of "faithfulness" should be an inclusive and open research, not a closed and self-sufficient system, for any theory cannot stay the same. We should treat translation theory from the view of development, and critically inherit the "faithfulness" of traditional translation theory, at the same time, absorb its essence, combining the translation practice with the points of view of deconstruction. What's more, the coexistence of various theories is the symbol of academic prosperity, why do we must choose an unique one among these standard? Academic study should avoid heading to a blind ally. When you think something in another way, maybe your confusion will be solved naturally, so does translation.

\section{REFERENCES}

[1] [1]Lefevere A. Translation, Rewriting and the Manipulation of Literary Fame[M]. London \& New York:Routledge, 1992.

[2] [2]Benjamin, Walter. The Task of Translator Gentzler [M].Edwin. Contemporary Translation Theories. London and New York : Routledge, 1993.

[3] [3]Nida, Eugene A. Towards a Science of Transiation [M] . Leiden: E. J.Briii, 1964: 1.

[4] [4]Bassnett, Susan. Transiation Studies [M ]. London and New York: Routiedge, 1988:3. 